\title{
Comparison of aspirin plus heparin with heparin alone on asymptomatic perioperative deep vein thrombosis in candidates for elective off-pump coronary artery bypass graft: A randomized clinical trial
}

Seyed Jalil Mirhosseini ${ }^{1}$, Seyed Khalil Forouzannia ${ }^{2}$, Seyed Mohammad Yousof Mostafavi Pour Manshadi ${ }^{3}$, Sadeq Ali-Hasan-Al-Saegh ${ }^{4}$, Nafiseh Naderi ${ }^{3}$, Mehdi Sanatkar ${ }^{5}$

${ }^{1}$ Department of Cardiovascular Surgery, Afshar Hospital, Shahid Sadoughi University of Medical Sciences, Yazd, Iran ${ }^{2}$ Yazd Cardiovascular Research Center, Shahid Sadoughi University of Medical Sciences, Yazd, Iran ${ }^{3}$ Department of Medicine, Ali ben Abitaleb Medical College, Islamic Azad University, Yazd, Iran ${ }^{4}$ (Medical Student), Yazd Cardiovascular Research Center, Afshar Hospital, Shahid Sadoughi University of Medical Sciences, Yazd, Iran ${ }^{5}$ Department of Anesthesiology, Razi Hospital, Tehran University of Medical Sciences, Tehran, Iran

\begin{abstract}
Background: Symptomatic or asymptomatic deep vein thrombosis (DVT) is a common complication following coronary artery bypass graft (CABG), in which less than $1 \%$ of these patients suffer from clinically evident pulmonary embolism (PE). DVT and PE can increase other morbidities of coronary revascularization from short to long period, but no clear consensus still exists regarding proper thromboprophylaxis strategy in the literatures. This study was designed to compare the anti-platelet prophylaxis of aspirin plus heparin with heparin alone on asymptomatic perioperative DVT in patients that are candidates for elective off-pump $C A B G$.
\end{abstract}

Methods: One hundred and twenty patients, who are candidates for elective off-pump $C A B G$, were randomly assigned to two groups: the aspirin plus heparin group (Group $1, n=60)$ that received $80 \mathrm{mg}$ daily aspirin orally and $5000 \mathrm{U}$ unfractionated heparin per $8 \mathrm{~h}$ subcutaneously from admission to discharge time, and the heparin group (group 2, $n=60$ ) that received same dose of heparin alone. All patients underwent right and left leg venous ultrasound examination during hospitalization, after which post-operative off-pump CABG complications such as deep vein thrombosis, bleeding and pulmonary embolism were evaluated in this study cases.

Results: The mean age of the patients was $62.10 \pm 10.71$ years with a male to female ratio of 2.24. Asymptomatic DVT occurred in 12 (10\%) patients who underwent elective off-pump CABG. DVT was found more in Group 2 (16.6\%) as compared to Group 1 (3.3\%) with statistical significant difference $(p=0.015)$. Bleeding was detected in $5(4.1 \%)$ cases in the patients sampled in this study $(p=0.34), 4$ cases of which are from Group 1 and 1 case from Group 2. However, PE was shown in none of this study cases.

Conclusions: The incidence of DVT decreased more with aspirin plus heparin as compared to heparin alone in patients who underwent elective off-pump CABG. As regards the results obtained in this study, more studies need to be conducted to establish this strategy for prophylaxis of DVT in CABG. (Cardiol J 2013; 20, 2: 139-143)

Key words: deep vein thrombosis, aspirin, CABG, heparin, anti platelet

Address for correspondence: Seyed Mohammad Yousof Mostafavi Pour Manshadi, MD, General Practitioner, Department of Medicine, Ali ben Abitaleb Medical College, Islamic Azad University, Yazd, Iran, tel: +98 913353 8922,

e-mail: s_m_yousof_mostafavi@yahoo.com

Received: 27.06.2012 Accepted: 25.10.2012 


\section{Introduction}

Coronary artery bypass graft (CABG) surgery is the most common cardiac surgery [1] and deep vein thrombosis (DVT) is a common cause of morbidity and mortality following CABG. DVT was reported in 70-80\% of patients who underwent open heart surgery, and can be asymptomatic [2-5]. Moreover, other morbidities which complicated the post-operative course immediately after DVT may cause complications for patients after they have been discharged from the hospital [2-5]. The ratio of upper limb to lower limb venous thrombosis was 6 fold [2-5]. Previous studies showed that predisposing factors for post-operative DVT are age, male sex, diabetes mellitus, hospitalization stay, cigarette smoking, hypercoagulophaty, familiar history of DVT and mechanical ventilation [6]. The incidence of post-operative DVT can be diminished with pharmacological prophylaxis. The common drugs for thromboprophylaxis are low molecular weight heparin (LMWH) and unfractionated heparin (UFH) [7-12]. Heparin can inhibit coagulation factors and fibrinolytic proteins but cannot affect primary hemostasis that occurs immediately after vessel constriction and platelet aggregation. Aspirin prevents the accumulation of platelet and inhibits primary hemostasis [7-12]. Previous trials indicated that preventing the scales of heparin alone on asymptomatic DVT was $60 \%$ to $70 \%$, and preventing the scales of asprin alone was $40 \%$ to $50 \%$ [13, 14]. This study was designed to compare the antiplatelet prophylaxis of aspirin plus heparin with heparin alone on asymptomatic perioperative DVT in patients who underwent elective off-pump CABG.

\section{Methods}

The prospective double blind randomized clinical trial performed in this study was approved by the ethics committee in our university. After receiving the written consent from patients, they participated voluntarily in off-pump CABG surgery from 14 August 2010 to 3 August 2011 in Afshar Cardiovascular Center, Yazd, Iran. All of the operations were performed by the one senior surgeon. The nurse (observer) who took the medicine to the patients (participants) and the patients themselves were blinded. Patients with a history of concomitant DVT, other cardiac surgery or planned anticoagulation (i.e., for atrial fibrillation or mechanical prosthetic valves), symptomatic DVT, history of PTE and candidates for on-pump CABG were excluded. The patients were randomly assigned into two groups: the aspirin plus heparin group (Group $1, \mathrm{n}=60$ ) which received $80 \mathrm{mg}$ aspirin orally on a daily basis and $5000 \mathrm{U}$ UFH per $8 \mathrm{~h}$ subcutaneously from admission to discharge time, and the heparin group (Group 2, $\mathrm{n}=60$ ) which received same dose of heparin alone. All patients underwent right and left leg venous ultrasound examination. Ultrasonography was performed by an experienced and expert physician using Acuson 128 or Sequoia ultrasound systems equipped with $4-\mathrm{MHz}$ and 7.5-MHz transducers with duplex and color Doppler capability. Both legs including the calf veins were scanned from the groin distally. The common femoral, deep femoral, superficial femoral and popliteal veins were imaged. Imaging of the calf veins was obtained both transversely and longitudinally, and confirmed with color-flow accentuation after the lower third of the calf was squeezed. The demographic variables and pre-operation and post-operation hemoglobin, hematocrit, platelet, activated clotting time (ACT), activated partial thromboplastin time (aPTT), prothrombin time (PT) and post-operation early complications such as bleeding and pulmonary embolism (PE), were recorded.

\section{Statistical analysis}

The individual who recorded the data did not know about the patients' groups. The data obtained in this study were analyzed by SPSS 16.5 software. We used ANOVA, $\chi^{2}$, Fisher exact test and T-test for quantitative and qualitative variables.

\section{Results}

One hundred and twenty patients with mean age of $62.10 \pm 10.71$, who are candidates for off-pump CABG surgery, enrolled in this study. Of these, $83(69.16 \%)$ patients were males and 37 $(30.8 \%)$ patients were females. The demographic characteristics of the patients are presented in Table 1. Of all the participants, asymptomatic DVT was observed in $12(10 \%)$ cases, $2(3.3 \%)$ cases of which were from Group 1 and $10(16.6 \%)$ cases were from Group $2(\mathrm{p}=0.015)$. Of the 12 cases with asymptomatic DVT, 9 were males and 3 were females. There was no significant relationship between sex and DVT after surgery ( $>0.05)$. The patients were divided into two age groups: less than 50 years old ( 14 cases) and above 50 years old (106 cases). Post-CABG DVT occurred in 1 case in the less than 50 year-old group, whereas it occurred in 11 cases in the above 50 year-old group. There 
Table 1. Demographic characteristics of both groups.

\begin{tabular}{lccc}
\hline Variables & Heparin & Hep + Asp & P \\
\hline Age [year] & $63.41 \pm 10.71$ & $60.80 \pm 10.64$ & 0.18 \\
Sex (male/female) & $42 / 18$ & $41 / 19$ & 0.84 \\
Hypertension & $30(50 \%)$ & $27(45 \%)$ & 0.58 \\
Diabetes mellitus & $28(46.7 \%)$ & $17(28.3 \%)$ & 0.06 \\
Cigarette smoking & $16(26.7 \%)$ & $16(26.7 \%)$ & 1.000 \\
Hyperlipidemia & $19(31.7 \%)$ & $24(40 \%)$ & 0.34 \\
Severe heart failure & $1(1.4 \%)$ & $1(1.7 \%)$ & 0.9 \\
Disability & $2(3.3 \%)$ & $0(0 \%)$ & 0.49 \\
Oral contraceptive drug & $5(14 \%)$ & $17(16 \%)$ & 0.29 \\
Valvular disease & $18(30 \%)$ & $26(43.3 \%)$ & 0.13 \\
Chronic obstructive pulmonary disease & $4(6.7 \%)$ & $3(5.0 \%)$ & 0.09 \\
\hline
\end{tabular}

Data presented as mean \pm standard deviation; Hep + Asp - heparin+aspirin

Table 2. Deep vein thrombosis in kinds of cardiac vessels involvements; $p=0.94$.

\begin{tabular}{lcc}
\hline Cardiac vessels involvements & Deep vein thrombosis & No deep vein thrombosis \\
\hline Single vessel & $1(10 \%)$ & $9(90 \%)$ \\
Two vessels & $2(8.3 \%)$ & $22(91.7 \%)$ \\
Three vessels & $9(11.5 \%)$ & $69(88.5 \%)$ \\
Left main coronary artery (LMCA) & 0 & $2(100 \%)$ \\
LMCA + three vessels & 0 & $5(100 \%)$ \\
LMCA + single vessel & 0 & $1(100 \%)$ \\
\hline
\end{tabular}

was no statistical significant relationship between DVT and age $(\mathrm{p}=0.18)$. The significant stenosis of $1,2,3$ and left main coronary artery (LMCA) disease alone, LMCA plus 3 vessels disease, LMCA plus single vessel disease in the patients, and the number of these patients with these involvements who suffered from DVT, are presented in Table 2. It was observed that no correlation was found between DVT and gender, diabetes mellitus, hypertension (HTN), hyperlipidemia (HLP), disability, cigarette smoking, history of utilization of oral contraceptive $(\mathrm{OCP})$, severe heart failure, chronic obstructive pulmonary disease (COPD), and valvular heart disease $(\mathrm{p}>0.05)$. There was no statistical significant difference between the pre- and post-operative ACT, aPTT and PT of the two groups ( $>$ > 0.05). In the study patients, post-operative bleeding was observed in $4(6.7 \%)$ cases in aspirin plus heparin group as compared to 1 (1.7\%) case in heparin alone group. It was observed that there was no significant statistical differences between the post-operative bleeding of the two groups $(\mathrm{p}=0.34)$. However, no cases were observed with pulmonary embolism in the patients during the post-operative period in both groups (Tables 3,4 ).

\section{Discussion}

Venous thromboembolism (VTE), which consists of DVT and PE, is a major cause of morbidity and mortality in patients undergoing open heart surgery $[15,16]$.

Without prophylactic anticoagulation, the frequency of DVT after cardiac surgery is high; however, with anticoagulation therapy, this incidence can be reduced significantly. The results of this study are in agreement with those of previous studies $[15,16]$ which indicated a relatively high rate of DVT after CABG in most cases without clinically significant symptoms. Goldhaber et al. [17] reported an incidence of approximately $22 \%$ DVT post-CABG. Nevertheless, specific guidelines for thromboprophylaxis after CABG surgery 
Table 3. Postoperation early complications in both groups.

\begin{tabular}{lccc}
\hline Variables & Heparin & Heparin + aspirin & P \\
\hline Deep vein thrombosis & $10(16.6 \%)$ & $2(3.3 \%)$ & 0.015 \\
Bleeding & $1(1.7 \%)$ & $4(6.7 \%)$ & 0.34 \\
Pulmonary embolism & $0(0 \%)$ & $0(0 \%)$ & 1.000 \\
\hline
\end{tabular}

Table 4. Preoperation and postoperation blood factors in both group.

\begin{tabular}{lccc}
\hline Variables & Heparin & Heparin + aspirin & P \\
\hline Hemoglobin (pre) & $13.52 \pm 1.32$ & $13.54 \pm 1.37$ & 0.93 \\
Hemoglobin (post) & $12.7 \pm 1.21$ & $12.6 \pm 1.46$ & 0.95 \\
Hematocrit (pre) & $42.26 \pm 4.34$ & $42.01 \pm 5.48$ & 0.78 \\
Hematocrit (post) & $36.4 \pm 3.88$ & $36.13 \pm 3.87$ & 0.66 \\
Platelet (pre) & $242.6 \pm 67.6$ & $244.8 \pm 64.6$ & 0.83 \\
Platelet (post) & $214.3 \pm 54.7$ & $204.08 \pm 57.8$ & 0.32 \\
\hline
\end{tabular}

Data presented as mean \pm standard deviation

are not currently available. Thromboprophylaxis interventions after CABG surgery, according to early passive and active mobilization, are periodic pneumatic compression, the routine use of antiplatelet therapy, and subcutaneous heparin in selected patients [18]. In patients who received heparin after cardiac surgery, prophylaxis may administer protection against VTE, especially in patients with ongoing risk factors. According to previous studies, the best choice for the efficacy of routine heparin prophylaxis in prevention of VTE after CABG is low molecular weight heparin, which is also cost effective [18].

The results of the meta-analysis performed by Mismetti et al. [19, 20] about the effect of LMWH on prevention of VTE indicated that LMWH can decrease this complication significantly. In a study conducted by Hovens et al. [21], aspirin was used as an antiplatelet as compared to placebo and it diminished thromboembolism significantly.

An animal study done by Chung et al. [22] reported that antiplatelet plus anticoagulation drug in rat model was more effective in the prevention of DVT to aspirin or heparin alone. This present study showed that administration of aspirin plus heparin in candidates of off-pump CABG surgery had more preventive effects on asymptomatic perioperative DVT than heparin alone. This study indicated that incidence of DVT was $16.6 \%$ in heparin group as compared to $3.3 \%$ in aspirin plus heparin group; therefore, antiplatelet drug can be appropriated synergic effects with heparin on diminishing DVT. The results of this study are similar to those obtained by Chung in his study. In this present study, sex, diabetes mellitus, HTN, HLP, disability, cigarette smoking, history of utilization of OCP, severe heart failure, COPD, involved vessels and valvular heart disease, were not correlated with the incidence of asymptomatic DVT ( $p>0.05)$. Also, it was found that bleeding had no statistical difference between the two groups $(\mathrm{p}=0.34)$.

Liau et al. [23] showed that surgical bleeding did not increase with the use of anticoagulation and antiplatelet agents for prevention of DVT. A study conducted by Sirvinskas et al. [24] reported that surgical bleeding in patients that received heparin was lower than those that received aspirin for the prevention of DVT. However, Veikutiene et al. [25] found that surgical bleeding in aspirin group was lower than that in heparin group. In this study, bleeding had no significant difference between the two groups. Also, it was observed that blood factors such as pre- and post-operation hemoglobin, hematocrit and platelet were similar in both groups.

A study carried out by Zibaeenezhad and Mazloum [26] reported that heparin infusion can significantly increase the occurrence of bleeding and vascular injury. In this present study, no patients suffered from PE in both groups. In a study done by Ambrosetti et al. [27], it was reported that PE following DVT was lower than one percent [27]. A possible limitation of this study could be the use of only a noninvasive imaging 
modality (ultrasonography) to detect DVT cases. Ultrasonography is used as a sensitive and specific diagnosis for proximal vein thrombosis such as thrombosis in the popliteal, femoral, and iliac veins in patients suspected of having a first episode of DVT $[28,29]$.

\section{Conclusions}

It can be concluded that aspirin plus heparin as compared to heparin alone, significantly reduced asymptomatic DVT following elective off-pump CABG and early post-operative complications such as bleeding or PE which had no significant difference between the two groups. Our results need to more studies to establish this strategy for prophylaxis of DVT in CABG.

\section{Acknowledgements}

This project is the result of medical thesis of Dr. Seyed Mohammad Yousof Mostafavi Pour Manshadi practicing as general practitioner.

\section{Conflict of interest: none declared}

\section{References}

1. Serruys PW, Morice MC, Kappetein P et al. Percutaneous coronary intervention versus coronary-artery bypass grafting for severe coronary artery disease. N Engl J Med, 2009; 360: 961-972.

2. Oger E. Incidence of venous thromboembolism: A community-based study in Western France. EPI-GETBP Study Group. Groupe d'Etude de la Thrombose de Bretagne Occidentale. Thromb Haemost, 2000; 83: 657-660.

3. Samama MM. An epidemiologic study of risk factors for deep vein thrombosis in medical outpatients: The Sirius study. Arch Intern Med, 2000; 160: 3415-3420.

4. Goldhaber SZ, Elliott CG. Acute pulmonary embolism, part I: Epidemiology, pathophysiology, and diagnosis. Circulation, 2003; 108: 2726-2729.

5. Dalen JE. Pulmonary embolism: What have we learned since Virchow? Natural history, pathophysiology, and diagnosis. Chest, 2002; 122: 1440-1456.

6. Holbrook A, Schulman S, Witt DM et al. American College of Chest Physicians. Evidence-based management of anticoagulant therapy: Antithrombotic Therapy and Prevention of Thrombosis, $9^{\text {th }}$ Ed. American College of Chest Physicians Evidence-Based Clinical Practice Guidelines. Chest, 2012; 141 (2 suppl.): e152S-e84S.

7. Paparella D, Galeone A, Venneri MT et al. Activation of the coagulation system during coronary artery bypass grafting: Comparison between on-pump and off-pump techniques. J Thorac Cardiovasc Surg, 2006; 131: 290-297.

8. Englberger L, Immer FF, Eckstein FS, Berdat PA, Haeberli A, Carrel TP. Off-pump coronary artery bypass operation does not increase procoagulant and fibrinolytic activity: Preliminary results. Ann Thorac Surg, 2004; 77: 1560-1566.

9. Raja SG, Dreyfus GD. Impact of off-pump coronary artery bypass surgery on postoperative bleeding: Current best available evidence. J Card Surg, 2006; 21: 35-41.
10. White RH, Keenan CR. Effects of race and ethnicity on the incidence of venous thromboembolism. Thromb Res, 2009; 123: S11-S17.

11. Cohen AT, Tapson VF, Bergmann JF et al. Venous thromboembolism risk and prophylaxis in the acute hospital care setting (ENDORSE study): A multinational cross-sectional study. Lancet, 2008; 371: 387-394.

12. Geerts WH, Pineo GF, Heit JA et al. Prevention of venous thromboembolism: the Seventh ACCP Conference on Antithrombotic and Thrombolytic Therapy. Chest, 2004; 126: 338S-400S.

13. Goldhaber SZ, Tapson VF. A prospective registry of 5,451 patients with ultrasoundconfirmed deep vein thrombosis. Am J Cardiol, 2004; 93: 259-262.

14. Mattos MA, Londrey GL, Leutz DW et al. Color-flow duplex scanning for the surveillance and diagnosis of acute deep venous thrombosis. J Vasc Surg, 1992; 15: 366-375.

15. Josa M, Siouffi SY, Silverman AB, Barsamian EM, Khuri SF, Sharma GV. Pulmonary embolism after cardiac surgery. J Am Coll Cardiol, 1993; 21: 990-996.

16. Shammas NW. Pulmonary embolus after coronary artery bypass surgery: A review of the literature. Clin Cardiol, 2000; 23: 637-644.

17. Goldhaber SZ, Hirsch DR, MacDougall RC, Polak JF, Creager MA, Cohn LH. Prevention of venous thrombosis after coronary artery bypass surgery (a randomized trial comparing two mechanical prophylaxis strategies). Am J Cardiol, 1995; 76: 993-996.

18. Tapson VF, Decousus H, Pini M et al. Venous thromboembolism prophylaxis in acutely ill hospitalized medical patients: Findings from the International Medical Prevention Registry on Venous Thromboembolism. Chest, 2007; 132: 936-945.

19. Mismetti P, Laporte-Simitsidis S, Tardy B et al. Prevention of venous thromboembolism in internal medicine with unfractionated or low-molecularweight heparins: A meta-analysis of randomized clinical trials. Thromb Haemost, 2000; 83: 14-19.

20. Mismetti P, Laporte S, Darmon JY, Buchmüller A, Decousus H. Meta-analysis of low molecular weight heparin in the prevention of venous thromboembolism in general surgery. Br J Surg, 2001; 88: 913-930.

21. Hovens MM, Snoep JD, Tamsma JT, Huisman MV. Aspirin in the prevention and treatment of venous thromboembolism. J Thromb Haemost, 2006; 4: 1470-1475.

22. Chung TL, Pumplin DW, Holton LH 3rd, Taylor JA, Rodriguez ED, Silverman RP. Prevention of microsurgical anastomotic thrombosis using aspirin, heparin, and the glycoprotein IIb/IIIa inhibitor tirofiban. Plast Reconstr Surg, 2007; 120: 1281-1288.

23. Liau JV, Ferrandis R, López Forte C. Antiplatelet agents and anticoagulants: Management of the anticoagulated surgical patient. Cir Esp, 2009; 85: 7-14.

24. Sirvinskas E, Veikutiene A, Grybauskas P et al. Influence of aspirin or heparin on platelet function and postoperative blood loss after coronary artery bypass surgery. Perfusion, 2006; 21: 61-66.

25. Veikutiene A, Sirvinskas E, Grybauskas P, Cimbolaityte J, Mongirdiene A, Veikutis V. Influence of preoperative treatment with aspirin or heparin on platelet function and intensity of postoperative bleeding in early period after coronary artery bypass surgery. Medicina (Kaunas), 2005; 41: 577-583.

26. Zibaeenezhad MJ, Mazloum Y. Heparin infusion after successful percutaneous coronary intervention: A prospective, randomized trial. Acta Cardiol, 2009; 64: 65-70.

27. Ambrosetti M, Salerno M, Zambelli M, Mastropasqua F, Tramarin R, Pedretti RF. Deep vein thrombosis among patients entering cardiac rehabilitation after coronary artery bypass surgery. Chest, 2004; 125: 191-196.

28. Kearon C, Julian JA, Newman T, Ginsberg JS. Noninvasive diagnosis of deep vein thrombosis. Ann Intern Med, 1998; 128: 663-677.

29. Tapson VF, Caroll BA, Davi dson BL et al. The diagnostic approach to acute venous thromboembolism. Clinical practice guideline. American Thoracic Society. Am J Respir Crit Care Med, 1999; 160: 1043-1066. 